\title{
Study of the regioselectivity of vicarious nucleophilic amination of mononitroquinolines with 1,1,1-trimethylhydrazinium iodide (TMHI)
}

\author{
Maria Grzegożek,* Barbara Szpakiewicz, and Piotr Kowalski \\ Institute of Organic Chemistry and Technology, Cracow University of Technology, ul. \\ Warszawska 24, PL-31155 Kraków, Poland \\ E-mail: magre@indy.chemia.pk.edu.pl
}

Dedicated to Professor Henk C. van der Plas on the occasion of his 80th anniversary

\begin{abstract}
The intermediary, covalent $\sigma$ adducts formed in the reaction of nitroquinolines with the ylide generated from 1,1,1-trimethylhydrazinium iodide (TMHI) were detected by ${ }^{1} \mathrm{H}$ NMR spectroscopy. Quantum-chemical calculations of the transition state (TS) energy and heats of formation of the $\sigma$ adducts were done. The results of the calculations agree with high regioselectivity observed for the amination of 3-, 5-, 6-, 7- and 8-nitroquinolines with (TMHI) via a vicarious nucleophilic substitution (VNS) reaction. High yields of the products substituted with amino substituent, mainly in the ortho position relation to the nitro group, are obtained.
\end{abstract}

Keywords: Nitroquinolines, 1,1,1-trimethylhydrazinium iodide (TMHI), vicarious nucleophilic substitution of hydrogen (VNS), covalent $\sigma$ adducts, quantum-chemical calculations, PM3 method

\section{Introduction}

In a previous paper $^{1}$ we reported that $\mathrm{x}$-nitroquinolines $(\mathrm{x}=3,5-8)$ 1a-e undergo direct amination with 1,1,1-trimethylhydrazinium iodide (TMHI) via vicarious nucleophilic substitution of hydrogen (VNS). The amination occurs regioselectively giving mainly the products with the amino groups in ortho position to the nitro group in high yields (61-95\%) and small amounts of the corresponding para isomers (Scheme 1) ${ }^{1}$. 


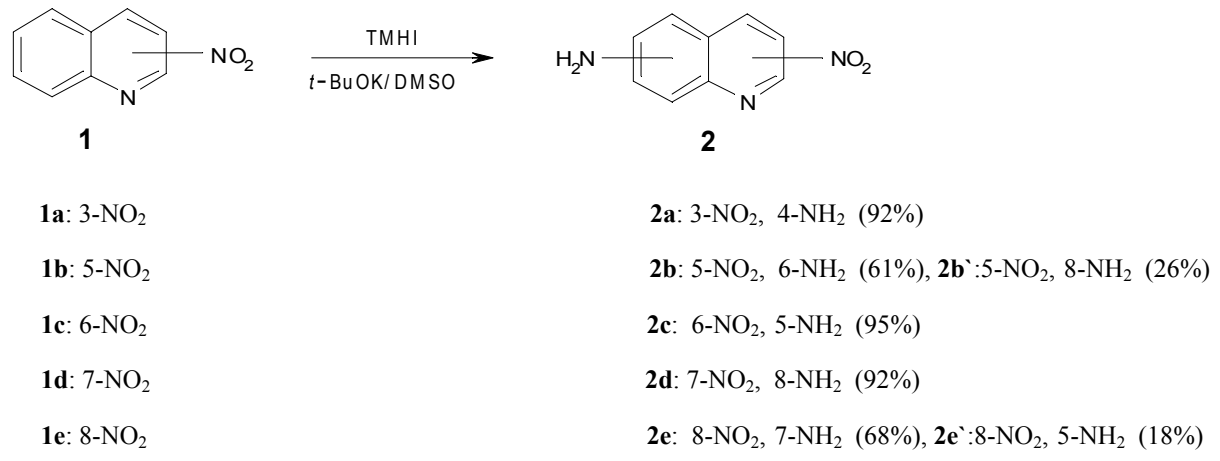

Scheme 1. The results of amination of mononitroquinolines 1a-e with TMHI ${ }^{1}$.

The reaction of nitroquinolines 1a-e with 1,1,1-trimethylhydrazinium iodide (TMHI) proceeds in accordance with the vicarious $\mathrm{S}_{\mathrm{N}} \mathrm{Ar}^{\mathrm{H}}$ mechanism, given by Mąkosza ${ }^{2,3}$ which is exemplified in Scheme 2. The reaction occurs between 5-nitroquinoline (1b) and the ylide (TMAI) generated from TMHI in the base-solvent system: potassium tert-butoxide - dimethyl sulfoxide at room temperature. In the initial step, TMAI adds to 5-nitroquinoline (1b) in the ortho and para positions relative to the nitro group to form $\sigma$ adducts with the structure comparable to Meisenheimer complexes. Next, these $\sigma$ adducts deprotonate with simultaneous elimination of trimethylamine to form anions, which upon protonation to yield the corresponding amino derivatives (Scheme 2).

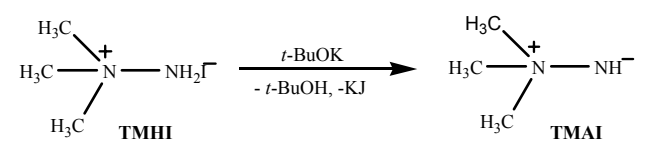

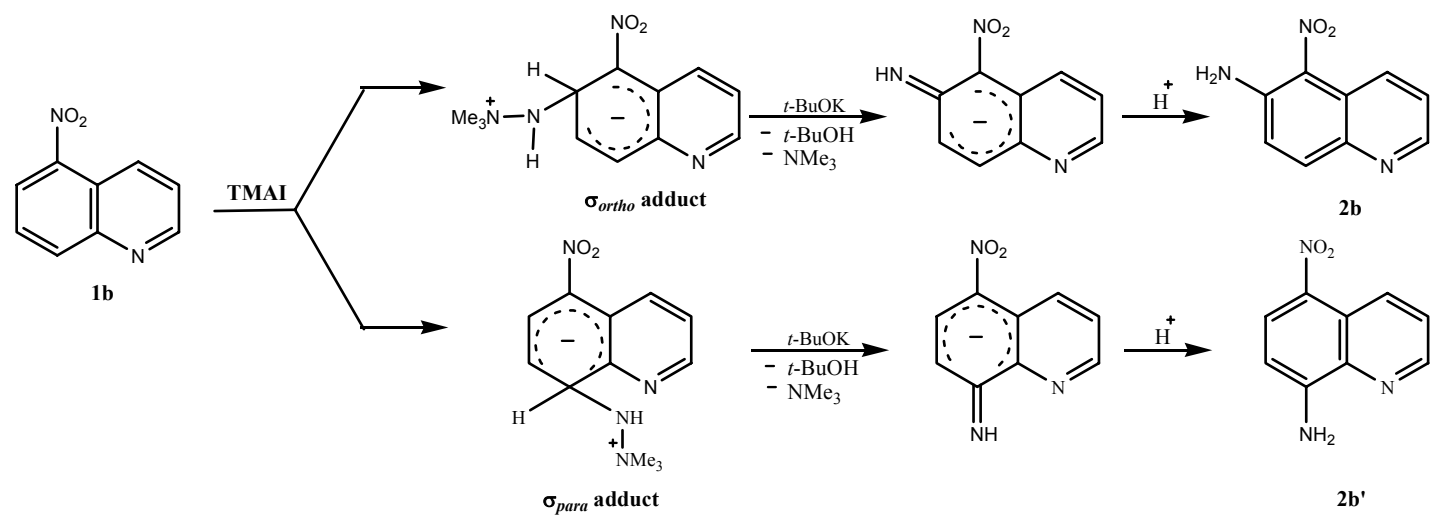

\section{Scheme 2}




\section{Results and Discussion}

To elucidate the mechanism of the vicarious dehydroamination (Scheme 2), we were able to detect the intermediary covalent $\sigma$ adducts and to determine their structures by ${ }^{1} \mathrm{H}$ NMR spectroscopy. We recorded the ${ }^{1} \mathrm{H}$ NMR spectra of the $\sigma$ adducts of nitroquinolines (1a-e) with the TMAI ylide, generated from 1,1,1-trimethylhydrazinium iodide in of $t$-BuOK/DMSO- $\mathrm{d}_{6}$ solution.

Comparison of the spectra of $\sigma$ adducts with those of the corresponding compounds 1a-e in a neutral solvents, such as DMSO- $\mathrm{d}_{6}$, shows that all proton signals in the $\sigma$ adducts are shifted to lower $\delta$-values in particular the signals of the protons at the carbon atoms, where the ylide (TMAI) was attached. The results are compiled in Table 1.

Table 1. ${ }^{1} \mathrm{H}$ NMR data of mononitroquinolines 1a-e and their $\sigma$ adducts with TMAI

\begin{tabular}{|c|c|c|c|c|c|c|c|c|}
\hline \multirow[t]{2}{*}{ Compound } & \multirow{2}{*}{$\begin{array}{l}\text { Solvent } \\
\Delta \delta\end{array}$} & \multicolumn{7}{|c|}{ Chemical shifts ( $\delta$ values $)$} \\
\hline & & $2-\mathrm{H}$ & $3-\mathrm{H}$ & $4-\mathrm{H}$ & $5-\mathrm{H}$ & $6-\mathrm{H}$ & $7-\mathrm{H}$ & $8-\mathrm{H}$ \\
\hline 3-Nitroquinoline (1a) & DMSO-d $_{6}$ & 9.66 & - & 9.04 & \multicolumn{4}{|c|}{$8.34-7.62^{*}$} \\
\hline $4-\mathrm{NH}-\mathrm{N}^{+}\left(\mathrm{CH}_{3}\right)_{3} \sigma$ adduct & $t$-BuOK/ & 8.79 & - & 5.80 & \multicolumn{4}{|c|}{$8.41-7.10^{*}$} \\
\hline of $1 \mathrm{a}$ & $\begin{array}{l}\text { DMSO- }_{6} \\
\Delta \delta\end{array}$ & 0.87 & - & 3.24 & \multicolumn{4}{|c|}{$-0.07-0.52^{*}$} \\
\hline 5-Nitroquinoline (1b) & $\mathrm{DMSO}^{-\mathrm{d}_{6}}$ & 9.10 & 7.83 & 8.85 & - & 8.36 & 8.01 & 8.36 \\
\hline $6-\mathrm{NH}-\mathrm{N}^{+}\left(\mathrm{CH}_{3}\right)_{3} \sigma$ adduct & $t$-BuOK/ & 8.14 & 7.16 & 9.34 & - & 4.22 & 7.03 & 6.80 \\
\hline of $\mathbf{1 b}$ & $\begin{array}{l}\text { DMSO- } \mathrm{d}_{6} \\
\Delta \delta\end{array}$ & 0.96 & 0.66 & -0.49 & - & 4.14 & 0.98 & 1.56 \\
\hline 6-Nitroquinoline (1c) & DMSO-d $_{6}$ & 9.15 & 7.78 & 8.73 & 9.08 & - & 8.50 & 8.23 \\
\hline $\begin{array}{l}5-\mathrm{NH}-\mathrm{N}^{+}\left(\mathrm{CH}_{3}\right)_{3} \sigma \text { adduct } \\
\text { of } \mathbf{1 c}\end{array}$ & $\begin{array}{l}t-\mathrm{BuOK}^{-} \\
\mathrm{DMSO}^{-\mathrm{d}_{6}}\end{array}$ & 8.50 & 7.15 & 7.64 & 4.19 & - & 7.74 & 6.20 \\
\hline & $\Delta \delta$ & 0.65 & 0.63 & 1.09 & 4.89 & - & 0.76 & 2.03 \\
\hline 7-Nitroquinoline (1d) & DMSO-d ${ }_{6}$ & 9.13 & 7.78 & 8.59 & 8.31 & 8.33 & - & 8.81 \\
\hline $\begin{array}{l}8-\mathrm{NH}-\mathrm{N}^{+}\left(\mathrm{CH}_{3}\right)_{3} \sigma \text { adduct } \\
\text { of } \mathbf{1 d}\end{array}$ & $\begin{array}{c}t-\mathrm{BuOK}^{-} \\
\mathrm{DMSO}^{-\mathrm{d}_{6}}\end{array}$ & 8.48 & 7.35 & 7.74 & 6.11 & 7.62 & - & 3.59 \\
\hline & $\Delta \delta$ & 0.65 & 0.43 & 0.85 & 2.20 & 0.71 & - & 5.22 \\
\hline 8-Nitroquinoline (1e) & $\mathrm{DMSO}^{-\mathrm{d}_{6}}$ & 9.07 & 7.78 & 8.61 & 8.36 & 7.79 & 8.26 & - \\
\hline $\begin{array}{l}\text { 7-NH-N }\left(\mathrm{CH}_{3}\right)_{3} \sigma \text { adduct } \\
\text { of } 1 \mathrm{e}\end{array}$ & $\begin{array}{l}t \text {-BuOK/ } \\
\text { DMSO-d }_{6}\end{array}$ & 8.31 & 6.83 & 7.52 & 6.89 & 6.58 & 4.24 & - \\
\hline & $\Delta \delta$ & 0.71 & 0.95 & 1.09 & 1.47 & 1.21 & 4.02 & - \\
\hline
\end{tabular}

* The signals of these protons form a complex multiplet and can not be exactly assigned.

Addition of TMAI to the $s p^{2}$ carbon atom of nitroquinoline induces change of its hybridization from $s p^{2}$ to $s p^{3}$ (tetrahedral centre of $\sigma$ adduct) which is reflected in a substantial shift of the NMR signals of the corresponding hydrogen atoms. These changes of the chemical shifts $(\Delta \delta=3.24-5.22 \mathrm{ppm})$ are comparable to those reported earlier for the amino $\sigma$ adducts detected in oxidative dehydroamination of nitroquinolines ${ }^{4-6}$. In the case of 5-nitro-(1b) and 8nitroquinoline (1e) we did not observe NMR signals from the $\sigma$ adducts linked at the position 
para to the nitro group. This indicates, their concentration was too low to be detectable by the NMR technique. ${ }^{7}$

In order to explain the high regioselectivity of the reactions studied, we carried out quantumchemical calculations of the reaction path using PM3 method. We calculated heats of formation of the $\sigma$ adducts linked at the ortho and para positions, relative to the nitro group. Moreover, we calculated the transition state (TS) energies for the reactions studied (Table 2). ${ }^{8}$

Table 2. Results of PM3 calculations: of bond lengths [a] and heats of formation $(\Delta \mathrm{H})$ of the transition states (TS) and the $\sigma$ adducts of the compounds 1a-e with TMAI

\begin{tabular}{|c|c|c|c|c|c|}
\hline Compound & & Transition State (TS) & $r_{1}$ & $\sigma$ adduct & $r_{2}$ \\
\hline \multirow{2}{*}{$1 \mathbf{a}$} & $\mathrm{C}-2$ & 99.94 & 2.01 & 94.51 & 1.56 \\
\hline & $\mathrm{C}-4$ & 96.17 & 2.04 & 88.04 & 1.53 \\
\hline \multirow{2}{*}{$1 \mathrm{~b}$} & C-6 & 102.26 & 1.98 & 96.17 & 1.54 \\
\hline & $\mathrm{C}-8$ & 103.47 & 2.07 & 91.69 & 1.52 \\
\hline \multirow{2}{*}{$1 \mathrm{c}$} & $C-5$ & 98.12 & 2.01 & 88.79 & 1.53 \\
\hline & $\mathrm{C}-7$ & 102.84 & 1.89 & 97.64 & 1.54 \\
\hline \multirow{2}{*}{ 1d } & C-6 & 103.68 & 1.87 & 99.18 & 1.54 \\
\hline & C-8 & 98.95 & 2.02 & 90.21 & 1.53 \\
\hline \multirow{2}{*}{ 1e } & $C-5$ & 101.93 & 1.96 & 95.73 & 1.54 \\
\hline & $\mathrm{C}-7$ & 101.37 & 1.93 & 97.48 & 1.55 \\
\hline
\end{tabular}

[a] $\mathrm{r}_{1}, \mathrm{r}_{2}$ - distance between the corresponding $\mathrm{C}$ atom in nitroquinoline 1a-e and the $\mathrm{N}$ atom in the ylide anion (TMAI) in transition state (TS) and $\sigma$ adduct respectively.

The calculated transition states energy and the heats of formation of the $\sigma$ adducts are in good agreement with the observed experimental results. In the case of 3-nitro- (1a), 6-nitro-(1c) and 7-nitroquinoline (1d), where two ortho positions relative to the nitro group are available, the substitution only in the ortho position with lower TS energy is observed. The calculated differences of TS energies for the formation of particular ortho products, are 3.77, 4.72 and 4.73 $\mathrm{kcal} / \mathrm{mol}$ for 1a, 1c and 1d respectively. Substantial differences are also observed for the heats of formation of the respective $\sigma$ adducts.

On the other hand, small TS energy difference for the reaction at the positions C-6 (ortho) 
and C-8 (para) $(1.21 \mathrm{kcal} / \mathrm{mol})$, calculated for 5-nitroquinoline (1b), agrees well with the experimental product distribution. In this case, the reaction mixture contained both isomers, while 6-amino-5-nitroquinoline (2b) with lower TS energy was the main product. Likewise, in the case of 8-nitroquinoline (1e), where the TS energy difference for the reaction at C-5 (para) and $\mathrm{C}-7$ (ortho) positions is $0.56 \mathrm{kcal} / \mathrm{mol}$, we obtained two products with 7-amino-8nitroquinoline (2e) being the main isomer.

The good agreement between the calculated transition states energies and the experimental results let us conclude that the reactions studied are under kinetic control.

\section{Conclusions}

In conclusion, the ${ }^{1} \mathrm{H}$ NMR study of the intermediate $\sigma$ adducts shows that for the studied nitroquinolines 1a-e, the position ortho to the nitro group is strongly favoured for nucleophilic attack. Additionally, the calculated energy of transition states (TS) and the heats of formation of the $\sigma$ adducts are consistent with experimentally observed regioselectivity of the vicarious amination of nitroquinolines with 1,1,1-trimethylhydrazinium iodide.

\section{References and Notes}

1. Grzegożek, M. J. Heterocycl.Chem. 2008, 45, 1879.

2. Mąkosza, M.; Wojciechowski, K. Liebigs Ann/Recueil 1997, 1805.

3. Mąkosza, M. Synthesis 1991, 103.

4. Tondys, H.; van der Plas, H.C.; Woźniak, M. J. Heterocycl. Chem. 1985, 22, 353.

5. Woźniak, M.; Barański, A.; Nowak, K. J. Org. Chem. 1987, 52, 5643.

6. Woźniak, M.; Grzegożek, M. Liebigs Ann.Chem. 1993, 823.

7. The ${ }^{1} \mathrm{H}$ NMR spectra were recorded on Varian Mercury 300 (300 MHz) spectrometer; the chemical shifts are given in ppm $(\delta)$.

8. The PM3 method was used for the semiempirical MO calculations using MOPAC- version 6 , molecular orbital package. The starting geometries and intermediary structures were obtained from the corresponding molecular models, fully optimized using keyword PRECISE. The trasition states TS were calculated using SADDLE subroutine. NLLSQ procedure was used for gradient optimization $(<0.1 \mathrm{kcal} / \mathrm{mol} / \AA)$. The calculations of TS were performed until at least one negative Hessian was obtained. Cartesian coordinates of the transition state TS for mononitroquinolines 1a-e involved in the reaction with TMAI are given in Supplementary Material S1. 